\title{
Quality or Quantity of Proteins in the Diet for CKD Patients: Does "Junk Food" Make a Difference? Lessons from a High-Risk Pregnancy
}

\author{
Alejandra Oralia Orozco-Guillien ${ }^{a}$ Cinthya Muñoz-Manrique ${ }^{b}$ \\ Maria Angelica Reyes-López ${ }^{b}$ Otilia Perichat-Perera ${ }^{b}$ Osvaldo Miranda-Araujoc \\ Claudia D'Alessandro $^{d}$ Giorgina B. Piccolie, ${ }^{f}$ \\ aNephrology Department, Instituto Nacional de Perinatología Isidro Espinosa de los Reyes, Mexico City, Mexico; \\ ${ }^{b}$ Nutrition and Bioprogramming Research Department, Instituto Nacional de Perinatología Isidro Espinosa de los \\ Reyes, Mexico City, Mexico; 'Department of Gynaecology and Obstetrics, Instituto Nacional de Perinatología Isidro

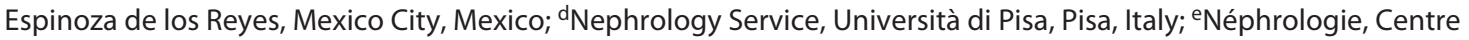 \\ Hospitalier Le Mans, Le Mans, France; fDepartment of Clinical and Biological Sciences, Università di Torino, Turin, Italy
}

\section{Key Words}

Chronic kidney disease · Diet · Pregnancy

\begin{abstract}
Background: How to manage patients with severe kidney disease in pregnancy is still a matter of discussion, and deciding if and when to start dialysis is based on the specialist's experience and dialysis availability. The effect of toxic substances usually cleared by the kidney may be more severe and readily evident. The review, and related case, underlines the importance of considering the presence of additives in food in delicate conditions, such as CKD pregnancy. The Case: A 39-year-old indigenous woman from a low-resourced area in Mexico was referred to the obstetric nephrology at 25 gestational weeks because of serum creatinine at $3.6 \mathrm{mg} / \mathrm{dL}$, hypertension on low-dose alpha-methyldopa, and nephrotic-range proteinuria. Kidney ultrasounds showed small poorly differentiated kidneys; foetal ultrasounds detected a female foetus, normal for gestational age. The patient's baseline protein intake, which was esti-
\end{abstract}

karger@karger.com www.karger.com/kbr

Karger $\stackrel{\text { ' }}{5}$

BOPEN ACCESS
(C) 2021 The Author(s)

Published by S. Karger AG, Basel

This article is licensed under the Creative Commons AttributionNonCommercial-NoDerivatives 4.0 International License (CC BYNC-ND) (http://www.karger.com/Services/OpenAccessLicense). Usage and distribution for commercial purposes as well as any distribution of modified material requires written permission. mated at $1.2-1.3 \mathrm{~g} / \mathrm{kg} /$ day, was mostly of animal-origin (>70\%) poor-quality food ("junk food"). In the proposed diet, protein intake was only slightly reduced (1.0-1.2 g/kg/ day), but the source of proteins was changed (only $30 \%$ of animal origin) with attention to food quality. A remarkable decrease in BUN was observed, in concomitance with adequate dietary follow-up, with rapid rise of BUN when the patient switched temporarily back to previous habits. A healthy female baby weighing $2,460 \mathrm{~g}$ ( 11 th centile for gestational age) was delivered at 37 gestational weeks. Discussion and Literature Review: While data on patients with chronic kidney disease are scant, the long list of contaminants present in food, especially if of low quality, should lead us to reflect on their potential negative effect on kidney function and make us realize that eating healthy, unprocessed "organic" food should be encouraged, in delicate conditions such as pregnancy and breastfeeding and for young children, in particular when kidney function is failing. The case herein described gave us the opportunity to reflect on the importance of diet quality and on the potential risks linked to food additives, many of which, including phos- 
phates and potassium, are not declared on food labels, while others, including dyes, antioxidants, thickeners, emulsifiers, and preservatives, are qualitatively, but not quantitatively, reported.

(C) 2021 The Author(s).

Published by S. Karger AG, Basel

\section{Background}

The early phases of human development, and the diseases occurring in these phases, are increasingly being recognized as sources of information about the future health of the mother and child [1-4]. In individuals without a known kidney disease, the hypertensive disorders of pregnancy point to an increased risk of future cardiovascular diseases and end-stage kidney disease [5, 6]. The hypertensive disorders of pregnancy may also often be the first indication of pre-existing CKD [7]. Conversely, patients with known CKD have an increased risk of hypertensive disorders in pregnancy due to not fully understood interactions between placental development, renal hyperfiltration, and reduction in nephron number [8]. How to manage patients with severe kidney disease in pregnancy is still a matter of discussion, and deciding if and when to start dialysis is based on the kidney specialist's experience and dialysis availability [9, 10]. While in highly resourced settings indications tend to favour an early start of dialysis, in poorly resourced ones, modulation of dietary habits may represent a safe alternative at least for a part of the patients [11-13]. Interestingly, in previous experiences, a carefully monitored moderate protein restriction was associated with preserved intrauterine growth [14]. Data from the overall population support these findings, suggesting that plant-based diets are safe in pregnancy and that adding proteins or amino acids to already protein-rich diets is almost paradoxically associated with foetal growth impairment [15-17].

Pregnancy in CKD is often psychologically stressful for the mother, the family, and caregivers. From the clinical point of view, pregnancy-induced hyperfiltration may increase proteinuria even in the absence of placental dysfunction $[18,19]$. Likewise, the effect of toxic substances may be more severe, and more easily detected, due to its effects on maternal kidney function and on foetal health; this is the case of some environmental pollutants, whose association with pregnancy outcomes can be taken as a proof of their effect on health $[20,21]$. The importance of considering the presence of additives in food in delicate conditions, such as CKD pregnancy, and the broader lessons we can learn from this experience are the issues we wish to discuss in this report.

In the nutritional management of advanced CKD, our attention progressively shifted from a quantitative approach, based on macronutrient intake (proteins, carbohydrates, and lipids), to a qualitative one, considering type of nutrient (plant-based vs. animal-based proteins, saturated or unsaturated fatty acids, short- vs. long-chain carbohydrates, etc.) as well as how nutrients are combined (Mediterranean diet, cafeteria diet, etc.) [22-25]. Furthermore, the problem of contaminants, preservation agents, trace elements, and pesticides is rapidly emerging, and their toxic effect is increasingly being recognized [26-28]. In this regard, CKD patients are a particularly interesting population, both because kidney disease may reduce excretion and enhance the toxicity of added substances and because a negative effect on the kidney function may be more readily evident in the presence of a reduced glomerular filtration rate, once the "buffering effect" of the renal functional reserve is offset.

The combination of advanced CKD and pregnancy is, therefore, not only a nutritional challenge but also a valuable occasion for highlighting, as though under a magnifying lens, the effect of dietary changes on health. In the case described, a pregnant woman with advanced CKD, was switched from "junk food" to a healthy diet and was able to avoid dialysis during pregnancy.

\section{The Case}

A 39-year-old indigenous woman affected by advanced CKD, born in Zacatepec, Oaxaca, and living in a remote low-resourced area in Mexico, was referred to the obstetric-nephrology department of the National Institute of Perinatology (INPER) in Mexico City in September 2019, at 25 gestational weeks. The woman, who lived with her husband's parents, was illiterate, as are many women of her age in remote rural areas, and had never worked outside her home. The pregnancy was her second one, but there were no available written records regarding her first pregnancy, which occurred in 2014. She recalled that she had delivered at term (41 weeks) by caesarean section because of preeclampsia. The baby, a girl, was born healthy and had regularly attained all the normal development milestones. The patient did not remember her birth weight, but she was apparently normal for gestational age.

While she was not aware she had CKD, upon careful inquiry, it seemed likely that kidney disease had been de- 
tected during the previous pregnancy, since, after delivery, she had been told that she should have periodic blood tests to determine whether there were problems in kidney function, which, for economic and logistic reasons, she had not performed. She was also advised to curtail her consumption of meat and had been prescribed erythropoietin.

She reported normal blood pressure, but controls were not frequent. She had also been advised that a future pregnancy would be a risk for her health.

When she became pregnant again, 5 years later, in March 2019, she moved to her mother-in-law's home because it was nearer to the nearest hospital ( $2 \mathrm{~h}$ away instead of 6-7 h). When she moved, she radically changed her dietary habits, switching from a homemade plant-based diet, using local fresh products, to a highcalorie diet, consisting mainly of sodas and processed, canned, and preserved food. She reported having gained between 5 and $7 \mathrm{~kg}$, in the first few weeks, which she later lost rapidly due to anorexia, nausea, and occasional vomiting.

She was initially referred to the local Centro de Salud Santa Maria Zacaltepec, where laboratory tests were performed and serum creatinine was found to be $3.6 \mathrm{mg} / \mathrm{dL}$. She was then referred to the local hospital, and since she would not accept a therapeutic interruption of pregnan$c y$, she was referred to INPER, for surveillance and, if necessary, dialysis start.

On referral to INPER, the physical examination revealed a woman who appeared to be in good health. She weighed $54 \mathrm{~kg}$ and was $148 \mathrm{~cm}$ tall (BMI: $24.7 \mathrm{~kg} /$ $\left.\mathrm{m}^{2}\right)$; her blood pressure was normal $(132 / 74 \mathrm{~mm} \mathrm{Hg})$ on low-dose alpha-methyl-dopa, and she had no oedema, in spite of nephrotic-range proteinuria (Table 1). Kidney ultrasounds showed small poorly differentiated kidneys, suggesting the presence of a chronic interstitial disease (Fig. 1). Foetal ultrasounds detected a female foetus, normal for gestational age, with normal uteroplacental and umbilical flows. Given normal foetal growth and the absence of clinical indications for dialysis and also considering the economic and logistic burden of dialysis, we decided to attempt a nutritional approach first, consisting in a plant-based diet, supplemented with vitamins, calcium, and erythropoietin.

The patient's baseline protein intake, which was estimated at $1.2-1.3 \mathrm{~g} / \mathrm{kg} /$ day, was mostly of animal origin $(>70 \%)$, but the assessment may have been affected by the consumption of poor-quality food ("junk food"), whose protein content may be lower than expected.

Diet in CKD Pregnancy: A Role for

Additives and Contaminants
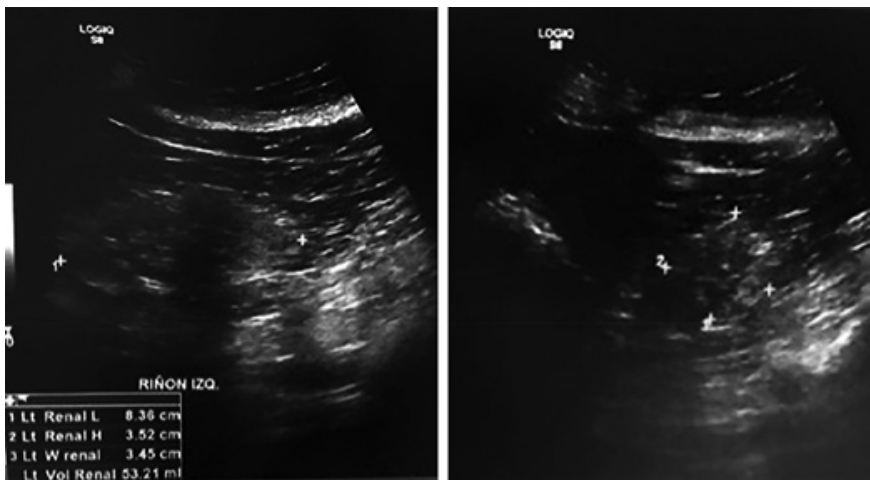

Fig. 1. Kidney ultrasounds showing small poorly differentiated kidneys, in line with a chronic, long-standing disease.

In the proposed diet, protein intake was only slightly reduced $(1.0 \mathrm{~g} / \mathrm{kg} /$ day $)$, but the source of proteins was changed (only $30 \%$ of animal origin), and the patient was also told to choose fresh fruits and vegetables and scheduled for strict checkups in the hospital (Table 2). Lowdose acetylsalicylate, folic acid, oral iron, and bicarbonate supplementation were started. One week later, laboratory findings had improved remarkably (Fig. 2; Table 1), with a striking reduction in BUN.

To be able to continue follow-up, the patient had moved to Mexico City with her husband, who had found a temporary job as a helper in a street food stall. They lived in a small room with shared access to a kitchen and had no refrigerator. Because of these economic and logistic constraints, at the subsequent control (28 weeks), while overall adhering to a plant-based diet, she had resumed a diet rich in packaged and junk food. Hypertension control was suboptimal. On account of the important logistic barriers, she accepted being hospitalized, so she would be able to follow the nutritional and treatment plan.

Throughout the following weeks, blood pressure remained well controlled on alpha-methyldopa (500 mg $\times$ 3 times per day). Serum creatinine remained overall stable; urea showed a trend towards a late increase, but remained lower than at referral (Table 1; Fig. 2). At 35 gestational weeks, weight gain was $4.1 \mathrm{~kg}$ since referral, and the diet was further modified, due to the onset of mild glucose intolerance. Foetal growth was normal throughout the pregnancy.

Caesarean section was planned at 37 weeks, on account of the presence of placenta accreta. A female baby weighing 2,460 g (11th centile for gestational age) was delivered, with an Apgar score of 7 at $1 \mathrm{~min}$ and 9 at 5 
Table 1. Biochemical data during pregnancy

\begin{tabular}{|c|c|c|c|c|c|c|c|}
\hline & $\begin{array}{l}25 \text { weeks at } \\
\text { referral, before } \\
\text { dietary plan }\end{array}$ & $\begin{array}{l}26 \text { weeks, } \\
1 \text { st week on } \\
\text { diet }\end{array}$ & $\begin{array}{l}28 \text { weeks, } \\
\text { partial dropout } \\
\text { from diet }\end{array}$ & $\begin{array}{l}32 \text { weeks, in } \\
\text { hospital care }\end{array}$ & $\begin{array}{l}35 \text { weeks, in } \\
\text { hospital care }\end{array}$ & $\begin{array}{l}37 \text { weeks, } \\
\text { delivery }\end{array}$ & $\begin{array}{l}2 \text { weeks after } \\
\text { delivery }\end{array}$ \\
\hline $\mathrm{BUN}, \mathrm{mg} / \mathrm{dL}$ & 69.1 & 36.4 & 46.7 & 51.4 & 54.2 & 56.1 & 46.7 \\
\hline e-GFR CKD-EPI, $\mathrm{mL} / \mathrm{min}$ & 13.3 & 13.7 & 11.5 & 14.6 & 14.1 & 13.7 & 14.1 \\
\hline Total proteins, g/dL & 6.5 & 6.4 & 6.6 & 6.3 & 6.3 & 6.2 & 6.2 \\
\hline Proteinuria, mg/day & 3,500 & 3,230 & 3,560 & 1,694 & 2,168 & 2,496 & 3,376 \\
\hline Haemoglobin, g/dL & 8.7 & 9.4 & 9.8 & 9.7 & 9.8 & 11.1 & 10.7 \\
\hline Calcium, mmol/L & 9.0 & 9.1 & 9.1 & 8.8 & 9 & 9 & 8.4 \\
\hline Uric acid, mg/dL & 7.5 & 6.7 & 7.8 & 8.6 & 7.6 & 6.7 & 6.9 \\
\hline $\mathrm{HCO}_{3}, \mathrm{mEq} / \mathrm{L}$ & 15 & 18 & 20 & 22 & 22 & 20 & 20 \\
\hline PTH, pg/mL & na & na & na & 145.3 & na & na & 327 \\
\hline Vitamin $\mathrm{D}, \mathrm{pg} / \mathrm{mL}$ & na & na & na & 45 & na & na & 50 \\
\hline Weight, kg & 54 & 54 & 54.5 & 55.5 & 57 & 58.1 & 56 \\
\hline $\mathrm{BP}, \mathrm{mm} \mathrm{Hg}$ & $136 / 80$ & $125 / 80$ & $138 / 81$ & $110 / 70$ & $100 / 70$ & $116 / 69$ & $126 / 72$ \\
\hline Antihypertensive therapy & $\begin{array}{l}\text { AMD } 500 \mathrm{mg} \\
\times 3\end{array}$ & $\begin{array}{l}\text { AMD } 500 \mathrm{mg} \\
\times 3\end{array}$ & $\begin{array}{l}\text { AMD } 500 \mathrm{mg} \\
\times 3 \mathrm{Niph} 30 \mathrm{mg}\end{array}$ & $\begin{array}{l}\text { AMD } 500 \mathrm{mg} \\
\times 3 \mathrm{Niph} 30 \mathrm{mg}\end{array}$ & $\begin{array}{l}\text { AMD } 500 \mathrm{mg} \times 3 \\
\text { Niph } 30 \mathrm{mg} \times 2\end{array}$ & $\begin{array}{l}\text { AMD } 500 \mathrm{mg} \times 3 \\
\text { Niph } 30 \mathrm{mg} \times 2\end{array}$ & Niph 30 mg \\
\hline
\end{tabular}

sCR, serum creatinine; GFR, glomerular filtration rate; PTH, parathyroid hormone; BP, blood pressure; AMD, alphamethyl dopa; Niph, niphedipine; ASA, acetylsalicylate; Vit D, 25-OH vitamin D; EPO, erythropoietin.

min. The baby was kept under observation in the neonatal intensive care unit on account of transient tachypnea of the newborn; the high bilirubin and uric acid levels detected responded to hydration and phototherapy. A small interventricular communication that was detected at birth spontaneously resolved after a few days; the baby was discharged in good clinical condition at 17 days of age.

The mother was discharged in stable clinical conditions 10 days after delivery (serum creatinine $3.84 \mathrm{mg} /$ dL). At the first follow-up visit, 1 week later, she felt well, blood pressure was fully controlled on Nifedipine, and kidney function and proteinuria were stable.
Subsequent follow-up was planned in the hospital nearest to her home; a nutritional plan with a plant-based diet and a moderate protein restriction was counselled, while potential family donors were evaluated, to make it possible to plan a pre-emptive transplantation in case of further deterioration in kidney function.

\section{Nutritional Management}

Diagnosis: excessive proportion of proteins of animal origin (70\%) related to poor choice and limited access and availability of fresh food. 
Table 2. First dietary plan

\begin{tabular}{lccccr}
\hline & Servings & Kilocalories & Proteins & Lipids & Carbohydrates \\
\hline Vegetables & 2 & 50 & 4 & 0 & 8 \\
Fruit & 3 & 180 & 0 & 0 & 45 \\
Fat-free cereals & 11 & 770 & 22 & 0 & 165 \\
Animal-derived food (low fat) & 3 & 120 & 21 & 3 & 0 \\
Whole milk & 1 & 150 & 9 & 8 & 12 \\
Oil without protein & 4 & 180 & 0 & 20 & 0 \\
Oil with protein & 2 & 140 & 6 & 10 & 6 \\
Overall & & $1,590 \mathrm{kcal}$ & $62 \mathrm{~g}$ & $41 \mathrm{~g}$ & $236 \mathrm{~g}$ \\
\hline
\end{tabular}

Distribution of protein intake: animal-derived proteins: $21 \mathrm{~g} / 34 \%$, plant-derived proteins: $41 \mathrm{~g} / 66 \%$.

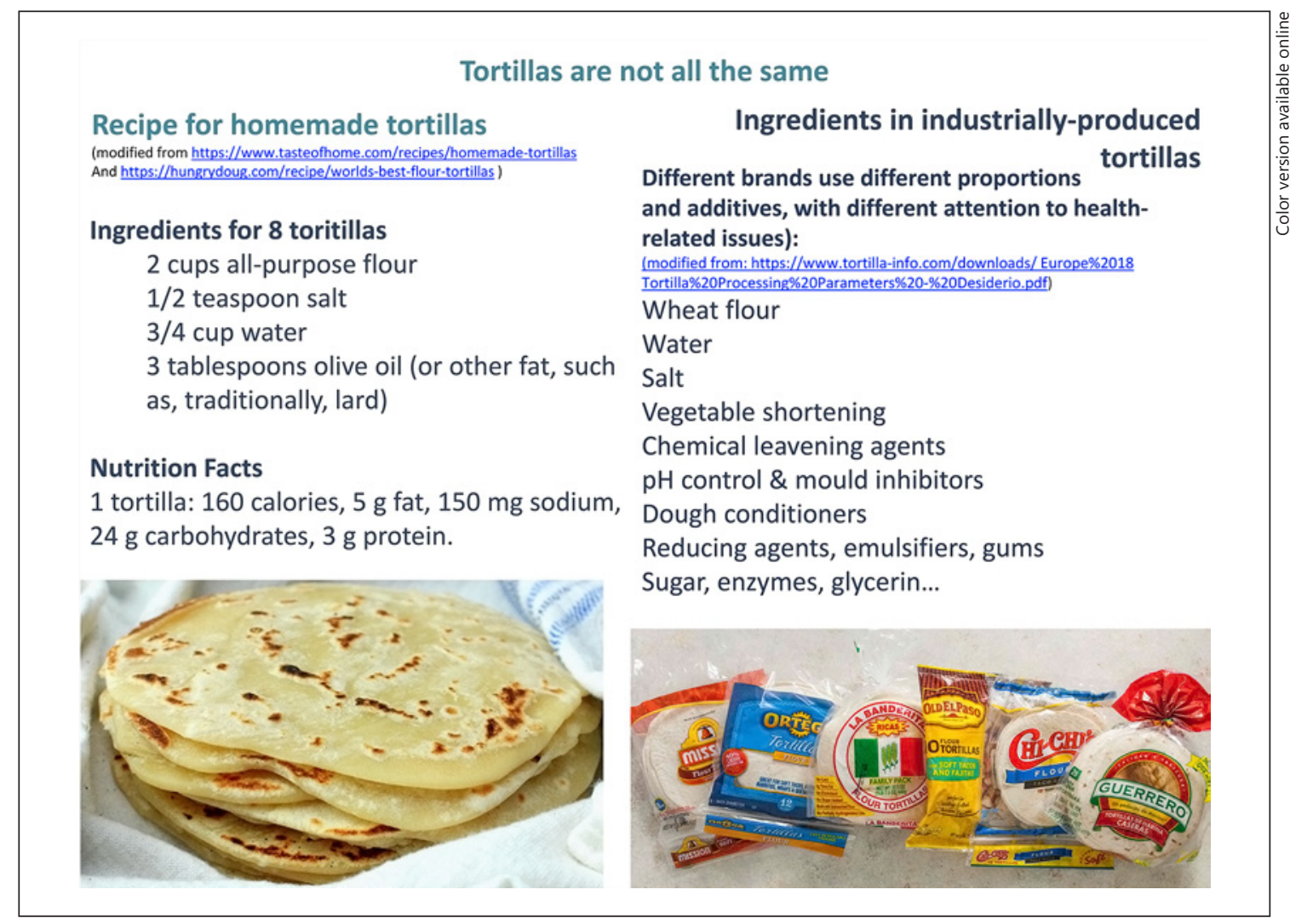

Fig. 2. Homemade and industrially produced tortillas.

Aims: to improve food choice, reducing animal-derived proteins (hamburgers, chicken, ready meals, etc.), returning to traditional habits, based on small quantities of different foods wrapped in tortillas.

The initial suggestions are reported in Table 2. Figure 1 reports the content of homemade and industrially produced tortillas.

Diet in CKD Pregnancy: A Role for Additives and Contaminants

\section{Discussion}

\section{The Case}

A plant-based diet is not a commercial "French fries diet," meaning with this a diet based on processed and "fast food" or even "junk food" even if of plant origin. The quality of the diet matters. 
Table 3. Main contaminants and their effect on health

\begin{tabular}{|c|c|c|}
\hline Contaminant & Food & Toxic effect \\
\hline $\begin{array}{l}\text { Metals: } \\
\text { Cadmium }\end{array}$ & Fish, vegetables, and cereals & $\begin{array}{l}\text { Accumulates in the bones and liver; can cause cancer and reproductive system } \\
\text { dysfunction; alters the development of the foetus in pregnancy }\end{array}$ \\
\hline Lead & & $\begin{array}{l}\text { Accumulates in the bones and can damage the central nervous system, kidneys, and } \\
\text { muscle system }\end{array}$ \\
\hline Mercury & & $\begin{array}{l}\text { Negatively affects brain development in infants; can accumulate in the kidneys, liver, } \\
\text { and central nervous system }\end{array}$ \\
\hline Arsenic & & $\begin{array}{l}\text { Can cause skin lesions, cancer, neurotoxicity, cardiovascular diseases, abnormal } \\
\text { glucose metabolism, and diabetes. There is emerging evidence of negative impacts on } \\
\text { foetal and infant development, particularly reduced birth weight }\end{array}$ \\
\hline Bisphenol A & Canned food & $\begin{array}{l}\text { Can cause hormone disruption, reproductive disorders, and delayed menarche in } \\
\text { females, infertility in males, and breast and prostate cancer }\end{array}$ \\
\hline Parabens & $\begin{array}{l}\text { Ubiquitous, used in food } \\
\text { preservation }\end{array}$ & $\begin{array}{l}\text { Have been hypothesized to have estrogenic properties and alter hormone metabolism } \\
\text { to contribute to endocrine disruption }\end{array}$ \\
\hline PFAS & Fish, vegetables, and cereals & $\begin{array}{l}\text { Have been shown to interact with blood proteins; are thought to cause pathological } \\
\text { responses and diseases, including cancer }\end{array}$ \\
\hline$N$-nitroso compounds & Cured meat & Have carcinogenic potential as they can form adducts with DNA \\
\hline Polycyclic aromatic hydrocarbons & Smoked meat & \\
\hline Heterocyclic aromatic amines & $\begin{array}{l}\text { Meat cooked at high } \\
\text { temperatures }\end{array}$ & \\
\hline
\end{tabular}

PFAS, per- and polyfluorinated alkyl substances.

The case discussed above is a good example of how pregnancy is an underexploited occasion for early diagnosis and follow-up of CKD and may show how pregnancy is an opportunity for reflecting on the importance of a nutritional approach that goes beyond considering quantity and type of proteins and involves attention to the quality of food.

Our patient was presumably diagnosed with CKD during her first pregnancy, yet she had only partially retained the information. In fact, while she had integrated the risks involved in a subsequent pregnancy, the diagnosis of CKD was not fully understood. In spite of the fact that CKD was long-standing and had gone untreated, the disease seemed clinically stable, as witnessed by her good clinical condition, well-controlled hypertension, and the lack of nephrotic syndrome at referral, thus making AKI on CKD unlikely (Fig. 1). Furthermore, her urea level was in keeping with the expected one in a patient on a mixed-protein diet and stage 4-5 CKD, making severe hypercatabolism unlikely (Table 1).

In this setting, the nutritional interview highlighted not only a high percentage of animal-derived proteins but also, and possibly more importantly, their low quality. Notably, nutritional intervention did not substantially reduce protein intake, but switched it from poor-quality animal-based to higher-quality plant-based sources (Table 2); conversely, the most important difference between the patient's diet at home and in the hospital was the quality of food (cheap, preserved food at home, vs. mainly fresh food, in the hospital, in keeping with INPER policy).

While it is not possible to formally distinguish between the effects of the lower "kidney toxicity" of plant-derived proteins versus the avoidance of added toxic substances, this case is strikingly similar to another one recently published by our team, regarding a young Italian woman, affected by a complex anomaly of the kidney and urinary 
Table 4. Main additives in food and their potential toxic effects

\begin{tabular}{|c|c|c|c|}
\hline Dyes & E100-E180 & \multirow{5}{*}{$\begin{array}{l}\text { Precooked or preserved } \\
\text { food, sauces, powder } \\
\text { dressings, nuts, preserved } \\
\text { and processed meat, } \\
\text { filled pasta (tortellini and } \\
\text { ravioli), concentrated } \\
\text { fruit juices, soft drinks, } \\
\text { processed cheeses, wine, } \\
\text { puddings, jellies, and } \\
\text { candy }\end{array}$} & $\begin{array}{l}\text { Carcinogenic potential; allergies; some are related to } \\
\text { hyperactivity in children }\end{array}$ \\
\hline Preservatives & E200-E297 & & High blood pressure, heart diseases, and cancer \\
\hline $\begin{array}{l}\text { Stabilizers, emulsifiers, and } \\
\text { thickeners }\end{array}$ & E400-E585 & & $\begin{array}{l}\text { Bowel distention and obstruction, malabsorption, } \\
\text { mucous membrane irritation, and worsening of kidney } \\
\text { and liver dysfunction }\end{array}$ \\
\hline Flavour enhancers & E620-E640 & & $\begin{array}{l}\text { Allergies and gastrointestinal dysfunction (diarrhoea, } \\
\text { vomiting, and nausea) }\end{array}$ \\
\hline Sweeteners & $\begin{array}{l}\text { E950-E967, } \\
\text { E420, E421 }\end{array}$ & & Potential carcinogenic effect and allergies \\
\hline
\end{tabular}

tract [11]. This patient was also managed in pregnancy by changing her eating behaviour, without changing protein intake, switching from a moderately protein-restricted diet in which at least half of the calories derived from junk food to a plant-based diet, rich in fresh food and vegetables. These 2 cases, coming from differently resourced settings, were both characterized by a rapid decrease in urea level, together with a favourable trend, mainly involving creatinine in the Italian patient and phosphate in the Mexican one [11].

Our patient was also treated by other common drugs in advanced CKD: for instance, erythropoietin, vitamin $\mathrm{D}$, and bicarbonate were added to treatment, and blood pressure control was optimized. However, none of these is effective in the short term on urea levels, and we considered that the metabolic effects observed were presumably due to the diet changes.

In both cases, the biochemical trends are not explained merely by the change in protein source, but suggest that the dietary changes had led to the avoidance of substances, such as polyphosphates or additives, that may exert a direct effect on kidney function. Notably, in both cases, in spite of advanced CKD, and in keeping with the importance of nutritional management, the babies were normal for gestational age and were born late preterm (the Italian case) or at term (the Mexican case).

Diet in CKD Pregnancy: A Role for

Additives and Contaminants

\section{Diet Quality and Additives}

A poor-quality diet is a source of substances that are potentially harmful to health. We can distinguish between substances that are intentionally added to food, such us additives, or preservation agents, and substances that are not intentionally added to food but result from chemical changes during food production, processing, packaging, or transport or come from environmental contamination (Tables 3,4). Both categories contain substances that are potentially harmful but the information we have is limited, for several reasons: some preservation agents, including phosphates and potassium, are not declared on food labels; interest in these agents is recent, and studies on humans are lacking. In animal studies, these compounds are often administered in higher doses and for short periods of time. Furthermore, in processed food, several additives are present at the same time, and disentangling the effect of each one may be difficult.

The main reasons why additives are added to food are to guarantee microbiological safety, extend shelf life, and maintain organoleptic characteristics. They are the consequence of the industrial production and distribution cycles: most of the food products in our everyday diet contain different amounts of additives of various chemical origins. In the USA, food additives must be authorized by the Food and Drug Administration (FDA), and in Europe, they must be authorized by the European Food Safety Author- 
ity (EFSA). The market has grown very rapidly recently, and in spite of the protective legal measures, concerns exist about their long-term safety [29-31]. By law, producers must declare the presence of additives on food labels, but are not obliged to indicate the amounts contained; their presence is often indicated with the letter "E" followed by a number that specifies a class (e.g., dyes, antioxidants, thickeners, emulsifiers, and preservatives) [32, 33].

Different adverse reactions, including, but not limited to, eosinophilic esophagitis, bronchial asthma, atopic dermatitis, contact dermatitis, chronic urticaria, anaphylaxis, metabolic syndrome, and inflammatory and bowel diseases, have been described $[29,30]$. Patients with reduced kidney function appear to be particularly prone to developing toxicity from many kinds of chemicals. However, data are scant and mainly regard phosphates; thus, the advantages of an additive-free diet, if one were actually possible, are not clear [31, 34-36].

Even less is known about contaminants unintentionally added to food or substances from polluted marine and agricultural food chains. Examples are the curing of meat with nitrite, which can produce $N$-nitroso compounds, and the smoking of meat which produces polycyclic aromatic hydrocarbons, while cooking at a high temperature produces heterocyclic aromatic amines: these chemicals have a carcinogenic potential [37-40]. Consumption of processed meat is associated with higher risk of chronic heart disease and diabetes mellitus [40, 41]. Seafood can contain significant amounts of mercury and arsenic, which are actively bio-accumulated; concentrations depend on the species, habitat, maturity, weight, and life span [42-44].

High cadmium concentration has been found in soil irrigated with wastewaters $[45,46]$. The kidney is the main organ affected by chronic cadmium exposure, and toxicity leads to a range of disorders from tubular proteinuria to renal failure $[47,48]$.

The list is long and still incomplete: for example, consumption of canned food has been related to increased urinary levels of bisphenol A, a synthetic chemical with various adverse effects on health, used in the production of polycarbonates in digital media (CDs and DVDs), sealants used by dentists, electronic equipment, tableware, and reusable bottles [49]. Its health hazards are linked to estrogenic activity that can lead to reproductive disorders, delayed menarche in females, infertility in males, and breast and prostate cancer [50]. Other adverse effects of early exposure are neurodevelopmental impairment with various manifestations, including attention deficiency, autism, and hyperactivity [51].
Consumption of food stored in plastic packaging leads to higher urinary levels of phthalate and its metabolites [52]. Phthalates are almost ubiquitous: 2-5 di (2-ethylhexyl)phthalate exposure occurs when contaminated food or water are consumed, while exposure to a number of phthalates (e.g., benzylbutyl phthalate or diethyl phthalate) occurs through contact with perfumes and deodorants. Exposure has been linked to thyroid derangements, increased oxidative stress, inflammation, and breast cancer $[53,54]$.

Conversely, fruits and vegetables have been identified as a major source of organophosphates, compounds widely used as pesticides, as they degrade easily under natural condition; however, content may still be high in ripe fruit. Residues have been detected in water, soil, and in products such as tea, sugar, vegetables, and fruits [55]. Parabens are antioxidants used in the preservation of foods, to extend their sell-by dates, and in the production of cosmetics and drugs, thanks to their antibacterial and antifungal properties. They are almost ubiquitous and have been found in soil, wastewater, rivers, and house dust; like phthalates, parabens may have estrogenic properties [56, 57].

Per- and polyfluorinated alkyl substances are another group of compounds eliciting increasing interest. They are used in manufacturing fabrics, paper, and food containers and in the production of photographic films, firefighting foams, and household detergents. Recent studies have shown that the wastewater treatment system is also a significant source of perfluoroalkyl compounds, potentially cancerogenic. Plants can absorb these compounds, whose uptake varies depending on species, chain length, and functional group. For example, accumulation of perfluorooctanoic acid and perfluorooctane sulfonic acid has been found in potatoes and grains, while high levels of short-chain compounds have been found in fruits and green vegetables, fish, and seafood $[58,59]$.

While data on patients with chronic kidney disease are scant, the long list of contaminants discussed here should lead us to reflect on their potential negative effect on kidney function and make us realize that eating healthy, unprocessed "organic" food should be encouraged, in particular in delicate conditions such as pregnancy and breastfeeding and for young children, in particular when kidney function is failing. These nutritional aspects may add to the long list of elements to which a multidisciplinary team, fundamental in the management of highrisk pregnancies, has to pay attention in the care of patients with advanced CKD in pregnancy. 


\section{Conclusions}

This is a review based on a "one-case trial," and we have to be cautious in drawing generalized conclusions. However, the suggestions originating from the case history support an effort to modify unhealthy dietary habits, in patients with advanced CKD, in particular if pregnant. In this context, our review suggests that it is vital to focus attention not only on macronutrients (proteins vs. others) and on their sources (animal vs. plant based) but also on the overall quality of the food eaten (fresh vs. preserved), to try to improve overall and kidney health in CKD patients.

\section{Statement of Ethics}

The patient has given written informed consent to publish her case (including publication of images).

\section{Conflict of Interest Statement}

None of the authors has any financial or non-financial conflict of interest.

\section{Funding Sources}

The Centre Hospitalier Le Mans supported publishing and language review expenses.

\section{Author Contributions}

Study design: A.O.O.G. and G.B.P.; patient management: A.O.O.G., C.M.M., M.A.R.L., and O.M.A.; bibliographic search and literature review: C.D.A. and G.B.P.; images and tables: A.O.O.G., M.A.R.L., and C.D.A.; drafting: A.O.O.G. and G.B.P.; review and final approval: all authors.

\section{References}

1 Arabin B, Baschat AA. Pregnancy: an underutilized window of opportunity to improve long-term maternal and infant health-an appeal for continuous family care and interdisciplinary communication. Front Pediatr. 2017 Apr 13;5:69.

2 Cain MA, Salemi JL, Tanner JP, Kirby RS, Salihu HM, Louis JM. Pregnancy as a window to future health: maternal placental syndromes and short-term cardiovascular outcomes. Am J Obstet Gynecol. 2016 Oct;215(4):484-e14.

3 Piccoli GB, Alrukhaimi M, Liu ZH, Zakharova E, Levin A; World Kidney Day Steering Committee. Women and kidney disease: reflections on World Kidney Day 2018. Kidney Int. 2018 Feb;93(2):278-83.

4 Fox R, Kitt J, Leeson P, Aye CYL, Lewandowski AJ. Preeclampsia: risk factors, diagnosis, management, and the cardiovascular impact on the offspring. J Clin Med. 2019 Oct 4;8(10): 1625.

5 Covella B, Vinturache AE, Cabiddu G, Attini R, Gesualdo L, Versino E, et al. A systematic review and meta-analysis indicates long-term risk of chronic and end-stage kidney disease after preeclampsia. Kidney Int. 2019 Sep; 96(3):711-27.

6 Piccoli GB, Cabiddu G, Castellino S, Gernone G, Santoro D, Moroni G, et al. A best practice position statement on the role of the nephrologist in the prevention and follow-up of preeclampsia: the Italian study group on kidney and pregnancy. J Nephrol. 2017 Jun;30(3): 307-17.

7 Filali Khattabi Z, Biolcati M, Fois A, Chatrenet A, Laroche D, Attini R, et al. Chronic kidney disease in preeclamptic patients: not found unless searched for-is a nephrology evaluation useful after an episode of preeclampsia? J Nephrol. 2019 Dec;32(6):97787.

8 Cabiddu G, Castellino S, Gernone G, Santoro $\mathrm{D}$, Giacchino F, Credendino O, et al. Best practices on pregnancy on dialysis: the Italian study group on kidney and pregnancy. J Nephrol. 2015 Jun;28(3):279-88.

9 Rivera JCH, Pérez López MJ, Corzo Bermúdez CH, García Covarrubias L, Bermúdez Aceves LA, Chucuan Castillo CA, et al. Delayed initiation of hemodialysis in pregnant women with chronic kidney disease: logistical problems impact clinical outcomes. An experience from an emerging country. J Clin Med. 2019 Apr 8;8(4):475.

10 Wiles K, Chappell L, Clark K, Elman L, Hall $\mathrm{M}$, Lightstone $\mathrm{L}$, et al. Clinical practice guideline on pregnancy and renal disease. BMC Nephrol. 2019 Oct 31;20(1):401.

11 Attini R, Montersino B, Leone F, Minelli F, Fassio F, Rossetti MM, et al. Dialysis or a plant-based diet in advanced CKD in pregnancy? A case report and critical appraisal of the literature. J Clin Med. 2019 Jan 20;8(1): 123.

12 Nava J, Moran S, Figueroa V, Salinas A, Lopez $\mathrm{M}$, Urbina $\mathrm{R}$, et al. Successful pregnancy in a CKD patient on a low-protein, supplemented diet: an opportunity to reflect on CKD and pregnancy in Mexico, an emerging country. J Nephrol. 2017 Dec;30(6):877-82.

13 Attini R, Leone F, Montersino B, Fassio F, Minelli F, Colla L, et al. Pregnancy, proteinuria, plant-based supplemented diets and focal segmental glomerulosclerosis: a report on three cases and critical appraisal of the literature. Nutrients. 2017 Jul 19;9(7):770.

14 Attini R, Leone F, Parisi S, Fassio F, Capizzi I, Loi $\mathrm{V}$, et al. Vegan-vegetarian low-protein supplemented diets in pregnant CKD patients: fifteen years of experience. BMC Nephrol. 2016 Sep 20;17(1):132.

15 Pawlak R. To vegan or not to vegan when pregnant, lactating or feeding young children. Eur J Clin Nutr. 2017 Nov;71(11):1259-62.

16 Melina V, Craig W, Levin S. Position of the academy of nutrition and dietetics: vegetarian diets. J Acad Nutr Diet. 2016 Dec;116(12):1970-80.

17 Piccoli GB, Clari R, Vigotti FN, Leone F, Attini R, Cabiddu G, et al. Vegan-vegetarian diets in pregnancy: danger or panacea? A systematic narrative review. BJOG. 2015 Apr; 122(5):623-33.

18 Moran P, Baylis PH, Lindheimer MD, Davison JM. Glomerular ultrafiltration in normal and preeclamptic pregnancy. $\mathrm{J}$ Am Soc Nephrol. 2003 Mar;14(3):648-52.

19 Tanaka M, Iwanari S, Tsujimoto Y, Taniguchi K, Hagihara K, Fumihara D, et al. Pregnancy is a risk factor for secondary focal segmental glomerulosclerosis in women with a history of very low birth weight. Intern Med. 2017; 56(12):1537-41.

20 Stieb DM, Chen L, Eshoul M, Judek S. Ambient air pollution, birth weight and preterm birth: a systematic review and meta-analysis. Environ Res. 2012 Aug;117:100-11.

21 Smith LE, Prendergast AJ, Turner PC, Humphrey JH, Stoltzfus RJ. Aflatoxin exposure during pregnancy, maternal anemia, and adverse birth outcomes. Am J Trop Med Hyg. 2017 Apr;96(4):770-6. 
22 Heindel J, Baid-Agrawal S, Rebholz CM, Nadal J, Schmid M, Schaeffner E, et al. Association between dietary patterns and kidney function in patients with chronic kidney disease: a cross-sectional analysis of the German Chronic Kidney Disease Study. J Ren Nutr. 2020;30(4):296-304.

23 Chauveau P, Aparicio M, Bellizzi V, Campbell $\mathrm{K}$, Hong X, Johansson L, et al. Mediterranean diet as the diet of choice for patients with chronic kidney disease. Nephrol Dial Transplant. 2018 May 1;33(5):725-35.

24 Chan M, Kelly J, Tapsell L. Dietary modeling of foods for advanced CKD based on general healthy eating guidelines: what should be on the plate? Am J Kidney Dis. 2017 Mar;69(3): 436-50.

25 Cupisti A, Brunori G, Di Iorio BR, D'Alessandro C, Pasticci F, Cosola C, et al. Nutritional treatment of advanced CKD: twenty consensus statements. J Nephrol. 2018 Aug;31(4):457-73.

26 Calvo MS, Sherman RA, Uribarri J. Dietary phosphate and the forgotten kidney patient: a critical need for FDA regulatory action. Am J Kidney Dis. 2019 Apr;73(4):542-51.

27 Shutto Y, Shimada M, Kitajima M, Yamabe H, Saitoh Y, Saitoh H, et al. Inadequate awareness among chronic kidney disease patients regarding food and drinks containing artificially added phosphate. PLoS One. 2013 Nov 13:8(11):e78660.

28 Uribarri J, Calvo MS. Hidden sources of phosphorus in the typical American diet: does it matter in nephrology? Semin Dial. 2003 MayJun;16(3):186-8.

29 Laudisi F, Stolfi C, Monteleone G. Impact of food additives on gut homeostasis. Nutrients. 2019 Oct 1;11(10):E2334

30 Velázquez-Sámano G, Collado-Chagoya R, Cruz-Pantoja RA, Velasco-Medina AA, Rosales-Guevara J. [Hypersensitivity reactions to food additives]. Rev Alerg Mex. 2019 JulSep;66(3):329-39.

31 Watanabe MT, Araujo RM, Vogt BP, Barrett P, Caramori JCT. Most consumed processed foods by patients on hemodialysis: alert for phosphate containing additives and the phosphate-to-protein ratio. Clin Nutr ESPEN. 2016 Aug;14:37-41.

32 EEC: Council Directive on the approximation of the rules of the Member States concerning the colouring matters authorized for use in foodstuffs intended for human consumption. Available from: https://eur-lex.europa.eu/ l e gal-content/en/A L L / ? u ri = CELEX\%3A31962L2645 Accessed 2019 Dec 26.

33 Guidance document describing the food categories in Part E of Annex II to Regulation (EC) No 1333/2008 on Food Additives. June 2017. Available from: https://ec.europa.eu/ food/sites/food/files/safety/docs/fs_food-im- provement-agents_guidance_1333-2008_an nex2.pdf Accessed 2019 Dec 26

34 Chen W, Ducharme-Smith K, Davis L, Hui WF, Warady BA, Furth SL, et al. Dietary sources of energy and nutrient intake among children and adolescents with chronic kidney disease. Pediatr Nephrol. 2017 Jul;32(7): 1233-41.

35 de Fornasari ML, Dos Santos Sens YA. Replacing phosphorus-containing food additives with foods without additives reduces phosphatemia in end-stage renal disease patients: a randomized clinical trial. J Ren Nutr. 2017 Mar;27(2):97-105.

36 Ramos CI, Cuppari L. A new look at phosphorus intake: what do we eat here is what they eat there? J Bras Nefrol. 2019 Jan-Mar;41(1): 12-3.

37 Barry KH, Jones RR, Cantor KP, Beane Freeman LE, Wheeler DC, Baris D, et al. Ingested nitrate and nitrite and bladder cancer in Northern New England. Epidemiology. 2020; 31(1):136-44.

38 Kobayashi J. Effect of diet and gut environment on the gastrointestinal formation of $\mathrm{N}$ nitroso compounds: a review. Nitric Oxide. 2018 Feb 28;73:66-73.

39 Wang X, Lin X, Ouyang YY, Liu J, Zhao G, Pan A, et al. Red and processed meat consumption and mortality: dose-response metaanalysis of prospective cohort studies. Public Health Nutr. 2016 Apr;19(5):893-905.

40 Ornish D. Holy cow! What's good for you is good for our planet: comment on "Red meat consumption and mortality". Arch Intern Med. 2012 Apr 9;172(7):563-4.

41 Bellavia A, Stilling F, Wolk A. High red meat intake and all-cause cardiovascular and cancer mortality: is the risk modified by fruit and vegetable intake? Am J Clin Nutr. 2016 Oct; 104(4):1137-43.

42 Andayesh S, Hadiani MR, Mousavi Z, Shoeibi S. Lead, cadmium, arsenic and mercury in canned tuna fish marketed in Tehran, Iran. Food Addit Contam Part B Surveill. 2015; 8(2):93-8.

43 Rebelo FM, Caldas ED. Arsenic, lead, mercury and cadmium: toxicity, levels in breast milk and the risks for breastfed infants. Environ Res. 2016 Nov;151:671-88.

44 Filippini T, Malavolti M, Cilloni S, Wise LA, Violi F, Malagoli C, et al. Intake of arsenic and mercury from fish and seafood in a Northern Italy community. Food Chem Toxicol. 2018 Jun;116(Pt B):20-6.

45 Asgari K, Cornelis WM. Heavy metal accumulation in soils and grains, and health risks associated with use of treated municipal wastewater in subsurface drip irrigation. Environ Monit Assess. 2015 Jul;187(7):410.

46 Xue P, Zhao Q, Sun H, Geng L, Yang Z, Liu W. Characteristics of heavy metals in soils and grains of wheat and maize from farmland ir- rigated with sewage. Environ Sci Pollut Res Int. 2019 Feb;26(6):5554-63.

47 Johri N, Jacquillet G, Unwin R. Heavy metal poisoning: the effects of cadmium on the kidney. Biometals. 2010 Oct;23(5):783-92.

48 Vesey DA. Transport pathways for cadmium in the intestine and kidney proximal tubule: focus on the interaction with essential metals. Toxicol Lett. 2010 Sep 15;198(1):13-9.

49 Kang JH, Kondo F, Katayama Y. Human exposure to bisphenol A. Toxicology. 2006; 226(2-3):79-89.

50 Geens T, Goeyens L, Covaci A. Are potential sources for human exposure to bisphenol-A overlooked? Int J Hyg Environ Health. 2011; 214(5):339-47.

51 Vogel SA. The politics of plastics: the making and unmaking of bisphenol a "safety". Am J Public Health. 2009;99(Suppl 3):S559-66.

52 Onghena M, Van Hoeck E, Negreira N, Quirynen L, Van Loco J, Covaci A. Evaluation of the migration of chemicals from baby bottles under standardised and duration testing conditions. Food Addit Contam Part A Chem Anal Control Expo Risk Assess. 2016 May; 33(5):893-904.

53 Mínguez-Alarcón L, Hauser R, Gaskins AJ. Effects of bisphenol A on male and couple reproductive health: a review. Fertil Steril. 2016 Sep 15;106(4):864-70.

54 González-Castro MI, Olea-Serrano MF, Rivas-Velasco AM, Medina-Rivero E, OrdoñezAcevedo LG, De León-Rodríguez A. Phthalates and bisphenols migration in Mexican food cans and plastic food containers. Bull Environ Contam Toxicol. 2011 Jun;86(6): 627-31.

55 Katsikantami I, Colosio C, Alegakis A, Tzatzarakis MN, Vakonaki E, Rizos AK, et al. Estimation of daily intake and risk assessment of organophosphorus pesticides based on biomonitoring data: the internal exposure approach. Food Chem Toxicol. 2019 Jan;123: $57-71$.

56 Fujino C, Watanabe Y, Sanoh S, Hattori S, Nakajima H, Uramaru N, et al. Comparative study of the effect of 17 parabens on PXR-, CAR- and PPARa-mediated transcriptional activation. Food Chem Toxicol. 2019 Nov; 133:110792.

57 Domingo JL, Nadal M. Per- and Polyfluoroalkyl Substances (PFASs) in food and human dietary intake: a review of the recent scientific literature. J Agric Food Chem. 2017 Jan 25; 65(3):533-43.

58 Guo R, Sim WJ, Lee ES, Lee JH, Oh JE. Evaluation of the fate of perfluoroalkyl compounds in wastewater treatment plants. Water Res. 2010 Jun;44(11):3476-86.

59 Ghisi R, Vamerali T, Manzetti S. Accumulation of perfluorinated alkyl substances (PFAS) in agricultural plants: a review. Environ Res. 2019;169:326-41. 